\title{
Classification of the risk in the new financing framework of the Deposit Guarantee Systems in Europe: K-Means Cluster Analysis and Soft Computing
}

\author{
Pilar Gómez ${ }^{1}$, Antonio Partal ${ }^{1}$, Macarena Espinilla ${ }^{2}$ \\ ${ }^{1}$ Department of Financial Economics and Accounting, University of Jaén, \\ Jaén, 23071, Spain \\ E-mail:\{pigomez,apartal\}@ujaen.es \\ ${ }^{2}$ Department of Computer Science, University of Jaén, \\ Jaén, 23071, Spain \\ E-mail:mestevez@ujaen.es
}

Received 6 May 2016

Accepted 2 September 2016

\begin{abstract}
The guidelines published by the European Banking Authority in 2015 about the contributions to the Deposit Guarantee Systems, establish two approaches to classify the member entities' risk: the bucket method and the sliding scale method, allowing freedom to every Member State to decide which methodology to use. In this work, using the bucket method with two different clustering techniques, k-means and soft computing, in a sample that represents more than $90 \%$ of the deposits covered in the Spanish banking system during the 2008 to 2014 period, the differences in the distribution of the Deposit Guarantee Fund risk and in the entities' contributions is analyzed. The obtained results reveal important differences. Consequently, the technique chosen by each country will determine the contributions regime.
\end{abstract}

Keywords: Deposit Guarantee Systems, European banking system, banking regulation, risk classification, K-means, soft computing.

\section{Introduction}

Among the key aspects to secure the financial strength and prevent systemic crisis scenarios are, among others, ensure the safety of the depositors in the credit companies and ensure an orderly management of the bank insolvencies, objectives entrusted to the Deposit Guarantee System (DGS).

Due to the financial crisis, a profound change was boosted in the international regulatory standards aimed at building a more robust banking system, and thereby consolidate financial stability. In this sense the Basel III agreement drawn up by the Basel Committee on Banking Supervision aims to strengthen sound banking, establishing a closer relationship between levels of risk and capital entities. Entities operating at a higher risk should have higher own resources to cope with potential losses avoiding the bankruptcy of the entity.
Improve risk management is the basis of the changes in financial regulation, penalizing the institutions taking excessive risks.

The greatest efforts were directed at establishing new frameworks for bank resolution that avoided the authorities from subsequently coming to the rescue, with the consequent burden on the public resources. The pillars of this new agreement ${ }^{1}$ are four:

(i) The requirement for a greater absorption of losses.

(ii) The existence of effective resolution regimes.

(iii) A reinforced supervisory intensity.

(iv) Greater resistance of the market infrastructure.

In Europe, these Guidelines were recently incorporated through the Bank Recovery and Resolution Directive $(B R R D)^{2}$ that establishes the rules for the resolution of banks and large investment firms and the Directive on the Deposit Guarantee Systems (DDGS) ${ }^{3}$. Both rules 
establish that the Member States (EM) will require funds to establish ex contributions paid by banks.

The DDGS establishes, in its Article 13 (3), the commission to the European Banking Authority (EBA) to issue the guidelines specifying the methods for calculating the contributions to the Deposit Guarantee Systems (DGS) and, in particular, will have to include a calculation formula, the specific indicators, the kinds of risks for the members, the risk weights thresholds assigned to specific risk types and other necessary elements. These guidelines are based on the principles agreed upon at an international level, such as the BISIADI Basic Principles for Effective Deposit Insurance Systems $^{4}$ and the IADI General Guidance for the development of differential premiums ${ }^{5}$.

On May $28^{\text {th }} 2015$, the EBA publishes the final Guidelines 6 "About the methods of calculating the contributions to the Deposit Guarantee System", and specify five risk categories in order to ensure that a sufficiently wide range of the fundamental aspects in the activity of the entities are reflected in the risk classification: capital adequacy, liquidity and asset quality, business and management model and potential losses for the DGS.

The proposed methods are two, the Bucket Method and the Sliding Scale Method, the EBA allowing the Member Entities freedom to decide which method to use. However, this decision may lead to differences in the contributions by the entities depending on the country, and pose an impediment to the planned harmonization of the future common Guarantee Fund in the European Union.

This work shows how the application of different classification methodologies for a given DGS reflects different risk exposure distributions and consequently an uneven impact on the contributions to be made by the Member Entities. To do this, using the Bucket Method and two different methodologies to classify risk, Cluster analysis ${ }^{7,8}$ and Clustering techniques based on Soft Computing ${ }^{9,10}$, analyzes the differences in the risk distribution of the Deposit Guarantee Fund of Credit Institutions in Spain (FGDEC) and the impact on the Member Entities' contributions from 2008-2014.

The document is structured as follows. The following section presents a review of the related literature. Section 3 analyzes the relevant aspects of the new contributions regime. Section 4 presents the results. Finally, section 5 concludes the document.

\section{Background}

Internationally there is a consensus on the convenience of establishing financing systems based on risk measures to improve the deposit insurances' effectiveness. A system with these characteristics will allow defining fairer contributions based on the risk of every insured entity, contributing to a greater market discipline. Charging the banks a flat fee for the deposit insurance, often as a percentage of the deposits, has two major drawbacks. First, it encourages the bank's risktaking to maximize the benefits and second, it implies that the lower-risk banks are subsidizing the higher-risk ones ${ }^{11}$.

The literature proposes three possible approaches for calculating the contributions based on the risk profiles of the DGS members:

(i) Using a single indicators' model.

(ii) A multiple indicators' model.

(iii) A default risk model.

The first two models are based on accounting indicators to evaluate the risk profile of the DGS members. Indicators that cover commonly used key areas to evaluate the financial soundness of a bank, such as capital adequacy, liquidity, profitability and asset quality. While the first approach (single indicator model) uses a single indicator based on the accountancy of these categories (for example, the capital adaptation index under the Basel rules) to calculate the risk-based contributions, different studies in the academic field confirm the appropriateness of using the capital ratio or some of the methods established in Basel II to measure risk in order to establish an objective and consistent system of variable premiums ${ }^{12,13,14}$. The multiple indicator model adds information of different variables to obtain the adjustment coefficient. Currently, the Federal Deposit Insurance Corporation (FDIC) in U.S.A. uses a multiple indicator model based on the $\mathrm{CAMEL}^{\mathrm{a}}$ qualification system.

The credit risk models can be applied if the DGS are considered as holding creditors' portfolios represented by the banks. Therefore, the use of the option valuation theory originally proposed by Black and Scholes $(1973)^{15}$ and Merton (1973) $)^{16}$, is possible to fix the

\footnotetext{
${ }^{\text {a }}$ CAMEL is an acronym for the following five components of bank safety and soundness: capital sufficiency, asset quality, management quality, earnings and liquidity capability.
} 
price of the deposit insurance cost (Merton, 1977) ${ }^{17}$. Merton (1977) shows that a DGS can be seen as a sales option on the value of the Bank's assets with an exercise price equal to the value of its debt maturity. Many of the empirical studies generated by the Merton model focus on the issue of the over or underestimation of the deposit insurance ${ }^{18,19,20,21,22,23}$. For many banks, the most important drawback of these models is the lack of information on the market prices, which makes the model difficult to apply in practice.

The EBA (2015) states that the DGS must comply with the following principles in developing their calculation methods:

(i) the contribution of each member institution must reflect the probability of default of the bank, as well as the potential losses arising from an intervention by the DGS

(ii) the contributions must be distributed as evenly as possible over time until the target level is reached, but with due consideration of the phase of the economic cycle and the procyclical impact that the contributions may have on the financial situation of the member banks;

(iii) in order to mitigate the moral risk, the incentives provided by the DGS must be compatible with the prudential requirements (i.e., the capital and liquidity requirements reflecting the risk of the member institution);

(iv) the calculation methods must take into account the banking sector's specific characteristics, and be compatible with the regulatory regime, the accounting practices and presentation of reports in the Member State in which the DGS is established;

(v) the rules for calculating the contributions must be objective and transparent;

(vi) the data necessary for calculating the contributions must not lead to excessive additional information requirements;

(vii) the confidential information must be protected; and finally,

(viii) the calculation methods must be consistent with the relevant historical data.

The annual contribution to a DGS by a credit entity must be calculated in the following way (EBA, 2015) by Eq. (1):

$$
C_{i}=C R \times A R W \times C D_{i} \times \mu
$$

where $C_{i}$ indicates the annual contribution of the member institution $i ; C R$ is the contribution rate (identical for all the member institutions in a given year); $A R W$ indicates the risk weight of all the institution member $i$; $C D$ indicates the deposits covered by the member institution $i$; and $\mu$ is the adjustment rate (identical for all the member institutions in a given year).

The contribution rate $(C R)$ is the percentage that a member entity should pay with a global risk weight $(A R W)$ equal to $100 \%$ (i.e., assuming there is no risk differentiation in the contributions), in order to meet the annual target level. The DGS will annually establish the contribution rate by dividing the annual target level ${ }^{\mathrm{b}}$ by the amount of the covered deposits of all the member entities.

The global risk weight for a member entity $i\left(A R W_{i}\right)$ will be determined according to the added risk score obtained by the entity $\left(A R S_{i}\right)$. The $A R S_{i}$ is equal to the sum of the risk weight scores of the different indicators. Two methods are proposed to calculate the $A R S_{i}$ and the assignment of the $A R W_{i}$ : Bucket Method and Sliding Scale Method. In the first, the classification of the risk follows a discrete scale (i.e., using buckets or classes). In the Sliding Scale Method, the classification of the risk follows a continuous scale (it does not require to differentiate buckets or classes).

Finally, the DGS must take into account the phase of the economic cycle and the procyclical impact that the contributions may have on the financial situation of the member institutions when they establish the annual target level. The cyclical adjustment must be made to avoid raising excessive contributions during the economic crises and to allow a more rapid accumulation of the DGS fund in times of economic prosperity.

In a banking system with relatively high-risk institutions, the sum of total annual contributions could be higher that the annual target level that year. Similarly, in a low risk banking system, the sum of total annual contributions would be lower than the annual target level. The adjustment coefficient tries to prevent this discrepancy. It should take into account the risk analysis undertaken by the relevant designated macroprudential authorities and reflect current economic conditions as well as medium-term perspectives, as persistent economic difficulties may

\footnotetext{
${ }^{\mathrm{b}}$ The annual target level must be established, at least, by dividing the amount of financing means the DGS needs to raise in a given year in order to reach the target level, for the remaining period of accumulation (expressed in years) to achieve the target level.
} 
not justify low contributions indefinitely. It may also consider the expected evolution in the covered deposits base.

\section{Risk Classification Methodology}

In this section, the sample considered for the study is described, and then the risk indicators that are selected. Finally, the two risk classifications are presented.

\subsection{Sample}

The sample considered for the study is made up of 363 credit entities adhered to the Deposit Guarantee Fund of Credit Institutions (FGDEC) from 2008-2014; with a representatively of over $90 \%$ of the covered deposits (Table 1). The information used comes from public documents of the Member Entities (annual accounts, reports and information of prudential relevance) and reports of the Deposit Guarantee Fund of Credit Institutions (FGDEC). We use consolidated information, because for some risk indicators is not available at the individual level ${ }^{\mathrm{c}}$.

\subsection{Selecting the Risk Indicators}

To evaluate the different risk categories (capital, liquidity, asset quality, business and management model and potential losses for the DGS), we consider the basic indicators proposed by the EBA (2015: 20) given in Table 2 . The information about the liquidity indicators is not available for the study period; proxies have been used from the accounting information available following the recommendations of the EBA ${ }^{\mathrm{d}}$ : LCR (Loans / Deposits), NSFR (Stable Financing / Stable Assets), and Liquidity Ratio (Liquid Assets / Total Assets). Table 3 shows some descriptive statistics of the sample in the analyzed period.

\subsection{Risk Classification: Cluster Analysis and Soft Computing Analysis}

The choice of the "Bucket Method" to calculate the ARW, involves defining a fixed number of buckets for each risk indicator by setting upper and lower limits for each one. The number of buckets for each risk indicator must be at least two, and reflect the different risk profiles of the member institutions (e.g., high, medium, low risk). An individual risk score (IRS), based on these risk levels, will be assigned to each bucket, ranging from 0 to 100 , where 0 indicates the lowest risk and 100 the highest. The limits of the buckets can be determined either relatively or absolutely.

Table 1. Representativeness of the sample

\begin{tabular}{lrrrrrrr}
\hline & $\mathbf{2 0 0 8}$ & $\mathbf{2 0 0 9}$ & $\mathbf{2 0 1 0}$ & $\mathbf{2 0 1 1}$ & $\mathbf{2 0 1 2}$ & $\mathbf{2 0 1 3}$ & $\mathbf{2 0 1 4}$ \\
\hline $\begin{array}{l}\text { Total covered deposits in } \\
\text { Spain (millions of Euros) }\end{array}$ & 736.3 & 781.1 & 790.3 & 792.3 & 794.8 & 796.9 & 788.3 \\
$\begin{array}{l}\text { Total covered deposits in the } \\
\text { sample (millions of euros) }\end{array}$ & 651.7 & 730.7 & 686.9 & 790.1 & 781.7 & 791.8 & 781.5 \\
$\begin{array}{l}\text { Representativeness of the } \\
\text { sample }\end{array}$ & $88.5 \%$ & $93.5 \%$ & $86.9 \%$ & $99.7 \%$ & $98.3 \%$ & $99.4 \%$ & $99.1 \%$ \\
Number of banks & 53 & 69 & 47 & 56 & 49 & 45 & 44 \\
\hline
\end{tabular}

\footnotetext{
${ }^{\mathrm{c}}$ The values of the risk indicators must be calculated on an individual basis for each member entity. However, the value of the risk indicators must be calculated on a consolidated basis when the Member State makes use of the option provided for in Article 13 (1) of the Directive 2014/49/UE to allow the central body and all the credit institutions permanently affiliated to the central organism referred to in Article 10 (1) of the Regulation (UE) 575/2013, to be subject as a whole for the risk weighting determined for the central organism and its affiliated entities on a consolidated basis. When a member entity has received an exemption from the compliance with the capital and / or liquidity requirements on an individual basis in accordance with Articles 7,8 and 21 of the Regulation (UE) $575 / 2013$, the corresponding capital / liquidity indicators must be calculated at a consolidated or semi-consolidated level.
}

\footnotetext{
${ }^{d}$ Within each category, the calculation method must include the basic risk indicators specified in Table 2. Exceptionally, any of these indicators may be excluded when it is not available. In this case, the competent authorities must strive to use a proxy as appropriate as possible for the removed indicator (EBA, 2015:20).
} 
Table 2. Core risk indicators proposed by the EBA (2015)

\begin{tabular}{|c|c|c|c|}
\hline Category & Indicator & Description & $\begin{array}{l}\text { Expected sign } \\
\text { on bank risk }\end{array}$ \\
\hline \multirow[t]{3}{*}{ Capital } & Leverage ratio & Tier 1 capital/Total assets & Negative \\
\hline & Capital coverage ratio & $\begin{array}{l}\text { Actual common equity Tier } 1 \text { (CET1) ratio/ } \\
\text { Required CET1 ratio or, } \\
\text { Actual own funds/Required own funds }\end{array}$ & Negative \\
\hline & CET1 ratio & CET1 capital/Risk weighted assets (RWA) & Negative \\
\hline \multirow[t]{3}{*}{$\begin{array}{l}\text { Liquidity and } \\
\text { Funding }\end{array}$} & $\begin{array}{l}\text { Liquidity coverage ratio } \\
\text { (LCR) }\end{array}$ & $\begin{array}{l}\text { LCR ratio as defined in Regulation (EU) No } \\
575 / 2013 \text { once it becomes fully operational. }\end{array}$ & Negative \\
\hline & $\begin{array}{l}\text { Net stable funding ratio } \\
\text { (NSFR) }\end{array}$ & $\begin{array}{l}\text { NSFR ratio as defined in Regulation (EU) No } \\
575 / 2013 \text { once it becomes fully operational. }\end{array}$ & Negative \\
\hline & Liquidity ratio & Liquid assets/Total assets & Negative \\
\hline Asset quality & $\begin{array}{l}\text { Non-performing loans } \\
\text { (NPL) ratio }\end{array}$ & NPL/Total loans and debt instruments & Positive \\
\hline \multirow{2}{*}{$\begin{array}{l}\text { Business model } \\
\text { and management }\end{array}$} & RWA/TA ratio & RWA/Total assets & Positive \\
\hline & Return on assets (ROA) & Net Income/Total assets & Positive/Negative \\
\hline $\begin{array}{l}\text { Potential losses } \\
\text { for the DGS }\end{array}$ & $\begin{array}{l}\text { Unencumbered assets/ } \\
\text { covered deposits }\end{array}$ & $\begin{array}{l}\text { (Total assets - Encumbered assets)/ Covered } \\
\text { deposits }\end{array}$ & Positive \\
\hline
\end{tabular}

Source: EBA (2015)

Table 3. Descriptive statistics of risk indicators (2008-2014)

\begin{tabular}{|c|c|c|c|c|c|c|c|c|c|c|}
\hline & $\begin{array}{c}\text { Leverage } \\
(\%)\end{array}$ & $\begin{array}{c}\text { Capital } \\
\text { coverage } \\
(\%) \\
\end{array}$ & $\begin{array}{c}\text { CET1 } \\
(\%)\end{array}$ & $\begin{array}{c}\text { LTD } \\
(\%)\end{array}$ & $\begin{array}{c}\text { SF/SA } \\
(\%)\end{array}$ & $\begin{array}{c}\text { Liquidity } \\
\text { (\%) }\end{array}$ & $\begin{array}{l}\text { NPL } \\
(\%)\end{array}$ & $\begin{array}{c}\text { RWA/TA } \\
(\%)\end{array}$ & $\begin{array}{c}\text { ROA } \\
(\%)\end{array}$ & $\begin{array}{c}\text { UE/CD } \\
(\%)\end{array}$ \\
\hline Average & 6.80 & 178.44 & 12.34 & 92.44 & 149.67 & 25.78 & 5.62 & 58.69 & 0.07 & 406.89 \\
\hline Median & 5.95 & 158.35 & 10.63 & 92.04 & 113.73 & 19.23 & 4.42 & 60.06 & 0.32 & 303.27 \\
\hline $\begin{array}{l}\text { Standard } \\
\text { Deviation }\end{array}$ & 5.62 & 95.57 & 8.01 & 41.02 & 135.41 & 20.98 & 4.01 & 29.96 & 2.25 & 424.34 \\
\hline Minimum & 0.47 & 54.47 & 1.11 & 2.27 & 43.42 & 1.89 & 0.04 & 9.10 & -15.24 & 189.99 \\
\hline Maximum & 72.96 & 811.12 & 62.99 & 311.21 & 1117.29 & 95.87 & 23.00 & 441.94 & 12.03 & $1,197.5$ \\
\hline $\begin{array}{l}\text { Number of } \\
\text { observations }\end{array}$ & 363 & 363 & 363 & 363 & 363 & 363 & 363 & 363 & 363 & 363 \\
\hline
\end{tabular}

Note: Leverage is the leverage ratio (Tier 1 capital/total assets), Capital coverage is the capital coverage ratio (actual own funds/required own funds), CET1 is the CET1 ratio (CET1 capital/risk weighted assets), LTD is the loans-to-deposits ratio, $S T / S A$ is the stable funding/stable assets ratio, Liquidity is the liquidity ratio (liquid assets/total assets), $N P L$ is the non-performing loans ratio, $R W A / T A$ is the risk weighted assets/total assets ratio, $R O A$ is the return on assets (net income/total assets), $U E / C D$ is the unencumbered assets/covered deposits ratio

When the relative base is used, the banks' IRS depends on their risk position in the vis-à-vis relation to other institutions (i.e., banks with similar risk profiles can be assigned to different buckets). However, when the absolute base is used, the limits of the buckets are determined to reflect the degree of risk of a specific indicator, i.e., all of the institutions may end up in the same bucket if they all have the same degree of risk level) ${ }^{\mathrm{e}}$. We consider four buckets in our study, where bucket 1 indicates the lowest risk and bucket 4 the highest risk. As we assume a linear application of the IRS to the buckets, the assigned IRS are 0 (bucket 1), 33 (bucket 2), 66 (bucket 3) and 100 (bucket 4). To establish the limits of the buckets we use two

\footnotetext{
e However, the EBA (2015) states that the limits of certain buckets over the absolute base must ensure that there is enough and significant differentiation of the member institutions for each risk indicator.
} 
classification methodologies: Cluster Analysis and Soft Computing Analysis.

Cluster analysis is a methodology that is widely used among the unsupervised learning techniques whose aim is data analysis and its interpretation ${ }^{24}$. It aims at the separation of a set of data objects in a number of groups called clusters through a similarity measure, such that the data objects classified in the same cluster are more similar than any other data object belonging to another cluster ${ }^{7}$. Normally every cluster is represented by a prototype or cluster center that characterizes all the data objects belonging to this cluster. Different clustering algorithms obtain the cluster centers as the centroid of the data that belongs to that cluster. This analysis does not impose a priori restrictions on the structure of the data and does not require assumptions about the probabilistic nature (or independence) of the observations ${ }^{25}$. Although several strategies have been proposed to determine the clusters $^{26,27}$, the most common method is the relocation of k-means groups ${ }^{28,29}$.

In the k-means clustering, the formation begins with an initial division, and by means of successive tests, contrasts the effect the allocation of each of the data has on the residual variance to each group ${ }^{30}$. The minimum value of the variance determines a configuration of new groups with their respective means. It continues to reallocate the data objects to the new centroids, repeating the process until no transfer can reduce the variance or has reached another established stopping criterion. The analysis configures the groups maximizing, in turn, the distance between the centers of gravity and provides a predetermined number of excluding homogeneous clusters, with the maximum divergence between them. To carry out the k-means clustering of indicators from $2008-14^{\mathrm{f}}$, the Eq. (2) is used, where $d_{i j}$ is the similarity measure between observation $i$ and center $j$.

$$
\sum_{i} \sum_{j} d_{i j}
$$

f Before carrying out the cluster analysis we eliminate the extreme values of the sample, which could distort the formation of clusters. However, these observations are classified according to the limits established by the cluster analysis.
In the study, the SPSS program $^{\mathrm{g}}$ is used, which implements the algorithm described above with the following parameters:

- Number of clusters, $j=\{1, . ., 4\}$

- Initializing cluster centers $=$ Random

- Stop criterion $=$ Maximum number of iterations equal to 10

- Similarity measure $=$ Euclidean distance .

The traditional or crisp clustering methods, such as the k-means ${ }^{31}$, are partition methods in which every data object is assigned to a single cluster. However, this course of action does not always provide a convincing partitioned data representation and that is why; clustering methods based on soft computing techniques such as fuzzy clustering were later proposed ${ }^{32}$. In the fuzzy clustering methods, each data object may belong to multiple clusters with a membership degree ${ }^{7}$ between zero and one, the sum of the membership degrees of a data object to each cluster being equal to one. Every data object is associated with a membership degree for each cluster, if the membership degree is close to the value of one; such data object represents a high similarity with the data objects contained in that cluster while a degree close to zero membership implies a low similarity between them.

Fuzzy clustering methods are based on objective functions seeking cluster centers for a predefined number of clusters and assign the data objects a fuzzy membership degree for every cluster in an iterative process that minimizes the objective function ${ }^{9,10}$. A number of fuzzy clusters can be provided in the fuzzy version that represents the maximum number of fuzzy clusters to which every data object can belong, i.e., 0 being the membership degree of that object to the rest of the clusters. Among the most widely used fuzzy clustering methods is the Fuzzy C-Means ${ }^{33}$ algorithm that uses an optimization process in which the cluster centers and the data objects are updated to find a local optimum.

To carry out the Fuzzy C-Means clustering of indicators from 2008-14h , the Eq. (3) is used, where $u_{i j}$ is the membership of observation $i$ in cluster $j$, and $d_{i j}$ is

\footnotetext{
${ }^{\mathrm{g}}$ http://www-01.ibm.com/software/es/analytics/spss/

${ }^{h}$ Before carrying out the cluster analysis we eliminate the extreme values of the sample, which could distort the formation of clusters. However, these observations are classified according to the limits established by the cluster analysis.
} 
the similarity measure between observation $i$ and cluster center $j$.

$$
\sum_{i} \sum_{j} d_{i j}
$$

In this study, the following describes the parameters used to obtain the Fuzzy C-Means clusters for the sample of indicators from 2008-14 that have been carried out by using the R software ${ }^{\mathrm{i}}$ :

- $\quad$ Number of clusters $=4$

- Maximum number of fuzzy clusters $=2$

- Initializing cluster centers $=$ Random

- Stop criterion = Maximum number of iterations equal to 10

- Similarity measure $=$ Euclidean distance

The limits of the buckets obtained with the different analyzes by indicator are shown in Table 4 .
The added risk score (ARS) for $i$ bank is calculated by Eq. (4):

$$
A R S_{i}=\sum_{j=1}^{n} I W_{j} \cdot I R S_{j}
$$

where $I W_{j}$ denotes the weights assigned to each risk indicator, which must be the same for all the member entities of the DGS. The sum of the weights assigned to the risk indicators must be equal to $100 \%$.

In the case of only using key risk indicators to determine the contributions to the DGS, the EBA (2015) recommends assigning the following weights to the risk categories: capital, 24\%; liquidity and financing, 24\%; asset quality, $18 \%$; business and management model, 17\%; and, finally, the potential use of the DGS funds, $17 \%$.

The specific IW assigned to each risk indicator is presented in Table 5 .

\begin{tabular}{|c|c|c|c|c|c|}
\hline $\begin{array}{c}\text { Risk Indicator } \\
\text { (RI) }\end{array}$ & Analysis & $\begin{array}{l}\text { Bucket 1 } \\
(\text { IRS = 0) }\end{array}$ & $\begin{array}{c}\text { Bucket 2 } \\
(\text { IRS = 33) }\end{array}$ & $\begin{array}{c}\text { Bucket } 3 \\
(\text { IRS = 66) } \\
\end{array}$ & $\begin{array}{c}\text { Bucket } 4 \\
(\text { IRS }=100)\end{array}$ \\
\hline \multirow{2}{*}{ Leverage } & Cluster & $\mathrm{RI}>8 \%$ & $8 \% \geq \mathrm{RI}>6.1 \%$ & $6.1 \% \geq \mathrm{RI}>4.5 \%$ & $\mathrm{RI} \leq 4.5 \%$ \\
\hline & Soft Computing & $\mathrm{RI}>11.7 \%$ & $11.7 \% \geq \mathrm{RI}>6.8 \%$ & $6.8 \% \geq \mathrm{RI}>4.4 \%$ & $\mathrm{RI} \leq 4.4 \%$ \\
\hline \multirow{2}{*}{$\begin{array}{l}\text { Capital } \\
\text { coverage }\end{array}$} & Cluster & $\mathrm{RI}>196.1 \%$ & $196.1 \% \geq \mathrm{RI}>167.1 \%$ & $167.1 \% \geq \mathrm{RI}>140.5 \%$ & $\mathrm{RI} \leq 140.5 \%$ \\
\hline & Soft Computing & $\mathrm{RI}>180.6 \%$ & $180.6 \% \geq \mathrm{RI}>177.9 \%$ & $177.9 \% \geq \mathrm{RI}>143.7 \%$ & $\mathrm{RI} \leq 143.7 \%$ \\
\hline \multirow{2}{*}{ CET1 } & Cluster & $\mathrm{RI}>13.9 \%$ & $13.9 \% \geq \mathrm{RI}>10.8 \%$ & $10.8 \% \geq \mathrm{RI}>7.9 \%$ & $\mathrm{RI} \leq 7.9 \%$ \\
\hline & Soft Computing & $\mathrm{RI}>21.0 \%$ & $21.0 \% \geq \mathrm{RI}>12.4 \%$ & $12,4 \% \geq \mathrm{RI}>9.0 \%$ & $\mathrm{RI} \leq 9.0 \%$ \\
\hline \multirow{2}{*}{ LTD } & Cluster & $\mathrm{RI}<53.9 \%$ & $53.9 \% \leq \mathrm{RI}<92.9 \%$ & $92.9 \% \leq \mathrm{RI}<129.8 \%$ & $\mathrm{RI} \geq 129.8 \%$ \\
\hline & Soft Computing & $\mathrm{RI}<53.8 \%$ & $53.8 \% \leq \mathrm{RI}<92.2 \%$ & $92.2 \% \leq \mathrm{RI}<139.0 \%$ & $\mathrm{RI} \geq 139.0 \%$ \\
\hline \multirow{2}{*}{$\mathbf{S F} / \mathbf{S A}$} & Cluster & $\mathrm{RI}>201.5 \%$ & $201.5 \% \geq \mathrm{RI}>132.8 \%$ & $132.8 \% \geq \mathrm{RI}>90.9 \%$ & $\mathrm{RI} \leq 90.9 \%$ \\
\hline & Soft Computing & $\mathrm{RI}>422.2 \%$ & $422.2 \% \geq \mathrm{RI}>270.7 \%$ & $270.7 \% \geq \mathrm{RI}>114.9 \%$ & $\mathrm{RI} \leq 114.9 \%$ \\
\hline \multirow{2}{*}{ Liquidity } & Cluster & $\mathrm{RI}>41.7 \%$ & $41.7 \% \geq \mathrm{RI}>25.7 \%$ & $25.7 \% \geq \mathrm{RI}>14.7 \%$ & $\mathrm{RI} \leq 14.7 \%$ \\
\hline & Soft Computing & $\mathrm{RI}>58.4 \%$ & $58.4 \% \geq \mathrm{RI}>28.3 \%$ & $28.3 \% \geq \mathrm{RI}>15.3 \%$ & $\mathrm{RI} \leq 15.3 \%$ \\
\hline \multirow{2}{*}{ NPL } & Cluster & $\mathrm{RI}<3.7 \%$ & $3.7 \% \leq \mathrm{RI}<6.7 \%$ & $6.7 \% \leq \mathrm{RI}<10.4 \%$ & $\mathrm{RI} \geq 10.4 \%$ \\
\hline & Soft Computing & $\mathrm{RI}<3.4 \%$ & $3.4 \% \leq \mathrm{RI}<6.5 \%$ & $6.5 \% \leq \mathrm{RI}<10.7 \%$ & $\mathrm{RI} \geq 10.7 \%$ \\
\hline \multirow{2}{*}{ RWA/TA } & Cluster & $\mathrm{RI}<35.5 \%$ & $35.5 \% \leq \mathrm{RI}<56.6 \%$ & $56.6 \% \leq \mathrm{RI}<71.63 \%$ & $\mathrm{RI} \geq 71.63 \%$ \\
\hline & Soft Computing & $\mathrm{RI}<32.0 \%$ & $32.0 \% \leq \mathrm{RI}<52.2 \%$ & $52.2 \% \leq \mathrm{RI}<66.5 \%$ & $\mathrm{RI} \geq 66.5 \%$ \\
\hline \multirow{2}{*}{ ROA } & Cluster & $\mathrm{RI}>0.92 \%$ & $0.92 \% \geq \mathrm{RI}>0.56 \%$ & $0.56 \% \geq \mathrm{RI}>0.29 \%$ & $\mathrm{RI} \leq 0.29 \%$ \\
\hline & Soft Computing & $\mathrm{RI}>1.6 \%$ & $1.6 \% \geq \mathrm{RI}>0.4 \%$ & $0.4 \% \geq \mathrm{RI}>-1.6 \%$ & $\mathrm{RI} \leq-1.6 \%$ \\
\hline \multirow{2}{*}{ UE/CD } & Cluster & $\mathrm{RI}>433.7 \%$ & $433.7 \% \geq \mathrm{RI}>340.8 \%$ & $340.8 \% \geq \mathrm{RI}>277.4 \%$ & $\mathrm{RI} \leq 277.4 \%$ \\
\hline & Soft Computing & $\mathrm{RI}>970.0 \%$ & $970.0 \% \geq \mathrm{RI}>589,9 \%$ & $589,9 \% \geq \mathrm{RI}>335.5 \%$ & $\mathrm{RI} \leq 335.5 \%$ \\
\hline
\end{tabular}

Table 4. Buckets for risk indicators: Analysis Cluster y Analysis Soft Computing

i https://www.r-project.org/ 
Table 5. Weights for risk categories and risk indicators

\begin{tabular}{lr}
\hline Risk categories and risk indicators & Weights \\
\hline Capital & $24 \%$ \\
Leverage & $8 \%$ \\
Capital coverage & $8 \%$ \\
CET1 & $8 \%$ \\
Liquidity and funding & $24 \%$ \\
LTD & $8 \%$ \\
SF/SA & $8 \%$ \\
Liquidity & $8 \%$ \\
Asset quality & $18 \%$ \\
NPL & $18 \%$ \\
Business model and management & $17 \%$ \\
RWA/TA & $8.5 \%$ \\
ROA & $8.5 \%$ \\
Potential losses for the DGS & $17 \%$ \\
UE/CD & $17 \%$ \\
\hline
\end{tabular}

The risk scores (ARS) must be grouped into risk levels, and these have a weight assigned (ARW) to calculate the individual contribution of a bank to the DGS according to the expression [1]. Following the recommendations of the EBA (2015), we consider the following classes and risk weights: low risk, $50 \%$; medium risk, $100 \%$; high risk, $150 \%$ and very high risk, $200 \%$. For grouping risk scores and the definition of the risk types' limits, we once again use cluster analysis and soft computing. The obtained results are shown in Table 6.

Table 6. Risk classes: Cluster and Soft Computing.

\begin{tabular}{lccc}
\hline $\begin{array}{l}\text { Risk } \\
\text { class }\end{array}$ & ARW & Cluster analysis & $\begin{array}{c}\text { Soft Computing } \\
\text { analysis }\end{array}$ \\
\hline Low & $50 \%$ & ARS $<35.08$ & ARS $<35.89$ \\
Medium & $100 \%$ & $35.8 \leq$ ARS $<50.66$ & $38,89 \leq$ ARS $<57,42$ \\
High & $150 \%$ & $50.66 \leq$ ARS $<63.78$ & $57,42 \leq$ ARS $<69,98$ \\
$\begin{array}{l}\text { Very } \\
\text { high }\end{array}$ & $200 \%$ & ARS $\geq 63.78$ & ARS $\geq 69,98$ \\
\hline
\end{tabular}

\section{Results}

The use of both methodologies in the risk classification of the entities evidence appreciable differences in both risk distribution and the consequences of the entities' contributions to the Deposit Guarantee Fund of Credit Institutions (FGDEC).
From the results presented in Table 7, it is observed that the score for medium risk is higher with the soft computing analysis and a little more than half of the entities, they would have a risk score equal to or greater than 63.20 points, reducing to 54.53 with the cluster analysis. However, the degree of dispersion regarding the average is similar with both techniques.

Table 7. Descriptive statistics of ARS (2008-2014)

\begin{tabular}{lrr}
\hline ARS & Cluster Analysis & $\begin{array}{r}\text { Soft Computing } \\
\text { Analysis }\end{array}$ \\
\hline Average & 52.62 & 60.48 \\
Median & 54.53 & 63.20 \\
$\begin{array}{l}\text { Standard } \\
\text { Deviation } \\
\text { Coefficient of } \\
\text { variation }\end{array}$ & 14.70 & 15.45 \\
$\begin{array}{l}\text { Asymmetry } \\
\text { Kurtosis }\end{array}$ & 0,28 & 0,26 \\
Minimum & -0.605 & -1.050 \\
Maximum & 0.193 & 1.274 \\
Number of \\
observations
\end{tabular}

Both distributions have negative asymmetry, more pronounced with soft computing analysis. In Figure 1 and 2, we can see a greater accumulation of entities in the right lane with the soft computing classification, which shows a higher level of risk in the Deposit Guarantee Fund of Credit Institutions (FGDEC) with this classification procedure.

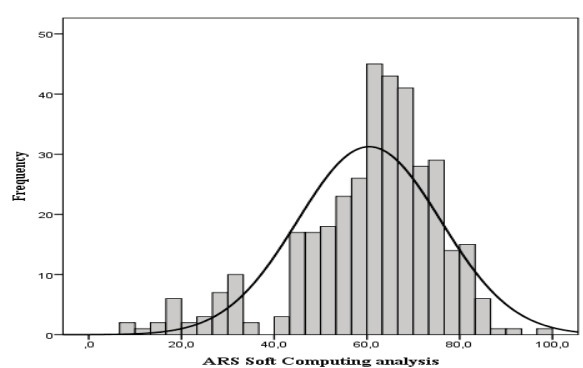

Fig. 1. Frequency distribution ARS with Soft computing 


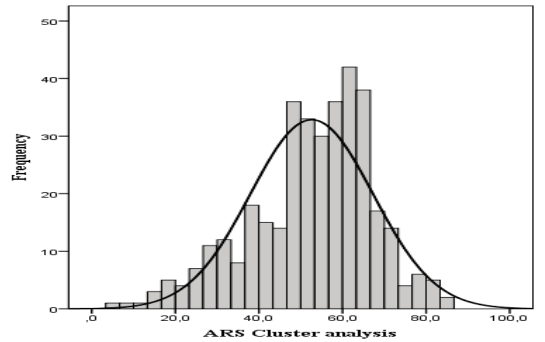

Fig. 2. Frequency distribution ARS with Cluster analysis

If we look at the distribution of covered deposits at the risk levels established by both techniques (Figure 3 ), and taking into account the level of risk associated with the DGS depending on the number of entities in each risk category and, the volume of covered deposits in each one, the distribution of the covered deposits present significant differences according to the classification procedure, mainly in the lanes. The entities classified as of low risk with the cluster analysis account for $13.4 \%$ of the Deposit Guarantee Fund of Credit Institutions (FGDEC) deposits, compared to the $0.4 \%$ of the soft computing analysis. The higher risk entities group $21.2 \%$ of the deposits covered with the soft computing analysis, compared to the $15 \%$ of the cluster analysis. Therefore, the distribution of the covered deposits represents a higher risk for the Deposit Guarantee Fund of Credit Institutions (FGDEC) when soft computing is used as a classification technique.

To reflect the above results in the total contributions to be undertaken by the entities to the Deposit Guarantee Fund of Credit Institutions (FGDEC), we

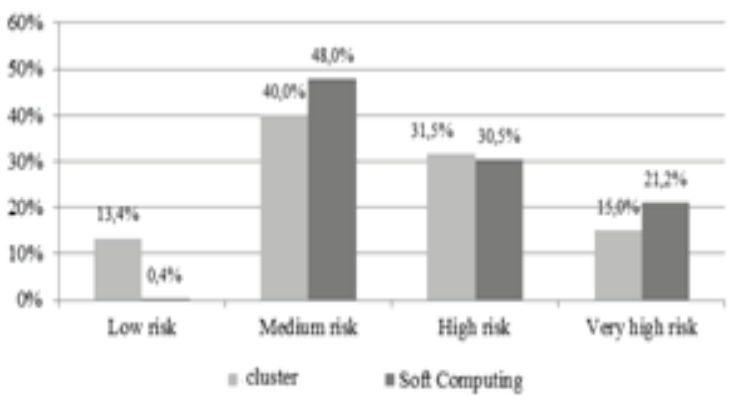

Fig. 3. Distribution of deposits covered risk levels (08-14)

calculate the risk-adjusted contributions according to the Eq. (1) from the classifications obtained with both analyzes. We determine the contribution rate (CR) needed to achieve the annual patrimony target level and the adjustment coefficient $(\mu)$ for every year to avoid the procyclicality of the contributions as established by the EBA (2015), the obtained results are shown in Table 8 .

To calculate the CR in the different years covered by the study, we have made the following considerations:

(i) In 2008, the FGDEC starts collecting contributions with the aim of achieving the target level of $0.8 \%$ of the deposits covered in 10 years (i.e., in 2017);

(ii) The contributions are distributed evenly from the initial period; and

(iii) Every year the contributions collected by the FGDEC will be equal to the annual target level set for that year.

Table 8. Contribution rates and adjustment coefficients

\begin{tabular}{|c|c|c|c|c|c|c|c|c|}
\hline & 2008 & 2009 & 2010 & 2011 & 2012 & 2013 & 2014 & 2008-14 \\
\hline Contribution rate (CR) & $0.080 \%$ & $0.081 \%$ & $0.080 \%$ & $0.084 \%$ & $0.084 \%$ & $0.085 \%$ & $0.083 \%$ & $0.082 \%$ \\
\hline $\begin{array}{l}\text { Total annual risk-unadjusted contributions } \\
\text { (millions of Euros) }\end{array}$ & 521,4 & 591,6 & 547,8 & 664,4 & 655,2 & 672,1 & 651,2 & 614,8 \\
\hline \multicolumn{9}{|l|}{$\begin{array}{l}\text { Total annual risk-adjusted contributions } \\
\text { (millions of Euros) }\end{array}$} \\
\hline i) Cluster analysis & 604,8 & 628,8 & 678,5 & 860,8 & 906,3 & 847,0 & 819,0 & 763,6 \\
\hline ii) Soft Computing analysis & 655,7 & 772,9 & 699,4 & 932,3 & 959,9 & 977,4 & 870,2 & 838,3 \\
\hline \multicolumn{9}{|l|}{ Adjustment coefficient $(\mu)$} \\
\hline i) Cluster analysis & 0.86 & 0.94 & 0.81 & 0.77 & 0.72 & 0.79 & 0.80 & 0.81 \\
\hline ii) Soft Computing analysis & 0.80 & 0.77 & 0.78 & 0.71 & 0.68 & 0.69 & 0.75 & 0.74 \\
\hline
\end{tabular}


Table 9. Effect of risk-adjusted contributions: Cluster analysis and Soft Computing analysis (2008-2014)

\begin{tabular}{|c|c|c|c|c|c|c|c|c|c|c|}
\hline & \multicolumn{5}{|c|}{ Cluster analysis } & \multicolumn{5}{|c|}{ Soft Computing analysis } \\
\hline & Banks & Mean & SD & Min. & Max. & Banks & Mean & SD & Min. & Max. \\
\hline $\begin{array}{l}\text { Banks that reduce their } \\
\text { contribution }\end{array}$ & $38.3 \%$ & $-32.8 \%$ & 20.7 & $-63.9 \%$ & $-5.9 \%$ & $34.4 \%$ & $-36.4 \%$ & 17.4 & $-65.9 \%$ & $-20.5 \%$ \\
\hline $\begin{array}{l}\text { Banks that increase their } \\
\text { contribution }\end{array}$ & $61.7 \%$ & $37.7 \%$ & 21.8 & $8.4 \%$ & $88.1 \%$ & $65.6 \%$ & $26.0 \%$ & 18.2 & $2.4 \%$ & $59.0 \%$ \\
\hline Low risk & $13.5 \%$ & $-59.6 \%$ & 3.0 & $-63.9 \%$ & $-53.0 \%$ & $9.6 \%$ & $-63.5 \%$ & 2.0 & $-65.9 \%$ & $-60.2 \%$ \\
\hline Medium risk & $24.8 \%$ & $-18.2 \%$ & 7.2 & $-27.7 \%$ & $-5.9 \%$ & $24.8 \%$ & $-25.8 \%$ & 4.1 & $-31.7 \%$ & $-20.5 \%$ \\
\hline High risk & $40.5 \%$ & $24.4 \%$ & 11.2 & $8.4 \%$ & $41.1 \%$ & $39.4 \%$ & $12.3 \%$ & 6.2 & $2.4 \%$ & $19.3 \%$ \\
\hline Very high risk & $21.2 \%$ & $63.1 \%$ & 12.4 & $44.6 \%$ & $88.1 \%$ & $26.2 \%$ & $46.6 \%$ & 8.1 & $36.5 \%$ & $59.0 \%$ \\
\hline
\end{tabular}

The total amount of the risk-adjusted contributions confirms the differences already detected in the risk distributions. Applying the soft computing methodology involves greater risk adjusted contributions than with cluster analysis, evidencing an increased risk for the Deposit Guarantee Fund of Credit Institutions (FGDEC). Finally, the amount to be raised cannot exceed the target level set by the Fund, being necessary to use the adjustment coefficient $(\mu)$ to determine the final contribution with both methodologies.

Finally, we evaluate the impact of the two classification methodologies on the Member Entities to the Deposit Guarantee Fund of Credit Institutions (FGDEC). To do this, we compare the contributions that each entity would have to make to the Deposit Guarantee Fund of Credit Institutions (FGDEC) to achieve the annual target level without considering the risk with the risk-adjusted contributions, from the relative change between the two contributions:

Change in bank contribution (\%) $=\frac{C_{i}^{M}-C_{0}}{C_{0}} \cdot 100$

Where $c_{0}$ contribution without risk to the planned annual target level, equal to the annual contribution rate for the deposits covered by the entity. $c_{i}{ }^{M}$ risk-adjusted contribution (according to Eq. (1)) in the different methods for risk classification. We analyze the differences between the classification methodologies from the following measures: Percentage of entities that would increase / decrease their contribution, increase / decrease average contributions and variation range (maximum increase and maximum decrease). The obtained results are shown in Table 9.
We found that during the periodunder review, most of the Member Entities would increase their contribution with the new risk-adjusted financing system (around 62\% with the cluster analysis and $66 \%$ with the soft computing analysis). In the cluster analysis the average increase in contributions would be higher $(37.7 \%)$ than in the soft computing analysis $(26 \%)$, it would also produce greater variations between the entities that increase their contribution. For high risk institutions, the average contribution would rise to 5.2 million Euros with the cluster analysis and 4.3 million Euros with Soft Computing analysis. On the contrary, for the entities that reduce contribution, the average decrease would be greater with the soft computing analysis $(36.4 \%)$ than in the cluster analysis $(32.8 \%)$. For low risk institutions the contributions decreased in 6 million Euros with Soft Computing analysis and 4.6 million with cluster analysis. The entities classified within the highest risk levels would have a greater penalty (would contribute more) with the cluster classification. While the entities that best manage their risk would benefit from greater reductions in their contributions to the soft computing classification.

\section{Conclusions}

Among the key aspects to strengthen financial stability and prevent systemic crisis scenarios are, among others, ensure the safety of the depositors in the credit entities and ensure an orderly management of the bank insolvencies, objectives entrusted to the DGS. The last major financial crisis showed that the DGS suffered from significant limitations, leading the European and 
international authorities to establish measures to improve their funding system while favoring the credit entities' market discipline. In this context the EBA, at the request of the European Commission, published the Guidelines on the methods of calculating the contributions to the Deposit Guarantee System adjusted to the risk of each entity with the aim of harmonizing the methods to establish contributions in all the Member Entities of the European Union and facilitate the future creation of the Single European Fund in 2015.

However, although the EBA proposes two calculation methods (Bucket Method and Sliding Scale Method) to determine the contributions of the entities to the DGS, instead it allows every country the discretion to decide on the methodology used to determine the risk of every entity and carry out, according to the reached level, the contributions to the system. This competence attributed to every Member Entity can assume significant differences when it comes to quantifying the risk of the DGS and consequently disparity in the contributions depending on every entity's country of origin.

This work, using the Bucket Method proposed by the EBA, applies two different methodologies to classify the risk for one and the same Deposit Guarantee System (Deposit Guarantee Fund of Credit Institutions), cluster analysis and soft computing analysis, and evidences the situation described above, the risk exposure distributions are different depending on the technique used and therefore a different effect on the contributions that the member entities would have to carry out. Several conclusions can be drawn from the analysis carried out for the regulator, although, the most relevant is the uneven impact when it comes to classifying the risk of every entity depending on the technique used and therefore the contributions to make according to the country where the entity is, having reason to believe that this arbitrariness is an important obstacle in the planned unification of the DGS in the EU.

It would be interesting to extend the effect of the proposal to the different DGS in the EU to determine the impact of the different classification methodologies in the risk profile of DGS of each country, especially when in the future it could be convenient to determine capital requirements of the DGS in line with Basel III recommendations for financial institutions.

\section{References}

1. Key Attributes of Effective Resolution Regimes for Financial Institutions, Financial Stability Board, 15 October 2014

2. Establishes a framework for the recovery and resolution of credit institutions and investment firms, European Parliament and of the Council, Directive 2014/59/EU, 15 May 2014.

3. Directive 2014/49/EU of the European Parliament and of the Council of 16 April 2014 on deposit guarantees schemes.

4. Core Principles for Effective Deposit Insurance Systems, Bank for International Settlements and International Association of Deposit Insurers, June 2009.

5. General Guidance for Developing Differential Premium Systems", International Association of Deposit Insurers, October, 2011.

6. Guidelines on methods for calculating contributions to deposit guarantee schemes, EBA/GL/2015/10.

7. Vladimir S. Cherkassky and Filip Mulier. 2007. Learning from Data: Concepts, Theory, and Methods (2nd ed.). John Wiley \& Sons, Inc., New York, NY, USA.

8. Jiawei Han, Morgan Kaufmann ,Data Mining: Concepts and Techniques (The Morgan Kaufmann Series in Data Management Systems), 2011.

9. A. Baraldi and P. Blonda, "A survey of fuzzy clustering algorithms for pattern recognition-Part I," IEEE Trans. Syst. Man Cybern. B, Cybern., vol. 29, no. 6, pp. 778 785, Dec. 1999

10. Karimi Azari, et al. (2011). Risk assessment model selection in construction industry, Expert Systems with Applications, 38, 9105-9111.

11. E. P. Bloecher et al, Options for pricing federal deposit insurance, FDIC Banking Review 15(4) (2003), pp. 1-17.

12. A. Sironi and C. Zazzara, Applying credit risk models to deposit insurance pricing: empirical evidence from the Italian banking system, Journal of International Banking Regulation 6(1) (2004), pp. 10-33.

13. J.P. Lee, Internal model-based capital standard and the cost of deposit insurance, Research in Finance 24 (2008), pp. 7-73.

14. M. Gilman, International deposit insurance, Economic Affairs 29(3) (2009), pp. 103-104.

15. F. Black and M. Scholes, The valuation of options and corporate liabilities, Journal of Political Economy 81(1973), pp. 637-659.

16. R. C. Merton, Theory of rational option pricing, Bell Journal of Economics and Management Science 4 (1973), pp.141-183.

17. R. C. Merton, An analytic derivation of the cost of deposit insurance and loan guarantees: an application of modern option pricing theory, Journal of Banking and Finance 1(1) (1977), pp. 3-11.

18. A. Marcus and I. Shaked, The valuation of FDIC deposit insurance using option-pricing estimates, Journal of Money, Credit, and Banking 16 (1984), pp. 446-460. 
19. D. Madan and G. Pennacchi, Introduction: special issue on pricing the risk of deposit insurance, Journal of Financial Services Research 24 (2003), pp. 89-110.

20. A. Episcopos, The implied reserves of the Bank Insurance Fund, Journal of Banking and Finance 28 (2004), pp.1617-1635.

21. A. Sironi, A. and C. Zazzara, Applying credit risk models to deposit insurance pricing: Empirical evidence from the Italian banking system, Journal of International Banking Regulation 6(1) (2004), pp. 10-33.

22. P. Campos et al. Un nuevo marco de seguro de depósitos para España. Estabilidad Financiera (12) (2007), pp. 93110.

23. D. Y. Hwang et al. The pricing of deposit insurance considering bankruptcy cost and closure policies, Journal of Banking and Finance (33) (2009), pp. 1909-1919.

24. W. Pedrycz, Clustering and Fuzzy Clustering, in Knowledge-Based Clustering. New York, NY, USA: Wiley, 2005, pp. 1-27.

25. C.K. Sørensen and J.M. Gutierrez, Euro area banking sector integration: Using hierarchical cluster analysis techniques. European Central Bank (W.P. 627, 2006).

26. L. Engelman and J.A. Hartigan, Percentage points of a test for clusters. Journal of American Statistical Association, 64(328) (1969), pp. 1647-1648.
27. H. Bozdogan, Choosing the number of component clusters in the mixture model using a new informational complexity criterion of the inverse Fisher information matrix (Springer-Verlag, Berlin, 1993), pp. 40-54.

28. J.B. MacQueen, Some methods for classification and analysis of multivariate observations, in Proc.5th Berkeley symposium on mathematical statistics and probability, (Berkeley: University of California, 1967), pp. 281-297.

29. J.A. Hartigan and M.A. Wong, Algorithm AS 136: A Kmeans clustering algorithm. Applied Statistics 28(1) (1978), pp. 100-108.

30. T. Papageorgiou et al., Business cycles synchronization and clustering in Europe (1960-2009), Journal of Economics and Business 62(5) (2010), pp. 419-470.

31. J. MacQueen, Some methods for classification and analysis of multivariate observations, in Proc. 5th Berkeley Symp. Mathemat. Statist. Probabil., Berkeley, CA, USA, 1967, pp. 281-197.

32. G. Klir and B.Yuan, Fuzzy Sets and Fuzzy Logic: Theory and Applications. Englewood Cliffs, NJ, USA: PrenticeHall, 1995.

33. J. Bezdek, Pattern Recognition With Fuzzy Objective Function Algorithms. (New York, NY, USA: Wiley, 2007). 